\title{
A Rare Shape of Placenta; Placenta Bipartite, Bilobata, Dimidiate, Duplex: A Rare Case Report
}

\author{
PRATIMA RANI BISWAS, GAUTOM KUMAR PAUL, MINA CHOWDHURY. MD. SELIM
}

\begin{abstract}
:
Placenta bipartite is a rare variation of placental morphology. The estimated incidence is up to 2-8 \% of pregnancy. There is no distinct racial, ethnic or geographical prediction observed. The diagnosis of an anomalous placenta is important for patient management at the time of delivery. Specifically, the bilobed placenta can be associated with first-trimester bleeding, polyhydramnios, abruption, and retained placenta. Careful attention to the cord insertion is also required for optimal fetal management. We report a case of a 24 years multi gravida with previous history of $2 \mathrm{C} / \mathrm{S}$ who had regular antenatal checkup and her pregnancy was uneventful till 36 wks. Her early USG at 16 weeks showed low lying placenta little away from the internal os of cervix. She was advised to take complete bed rest, avoid journey and coitus. Couple was warned about pervaginal bleeding, which may occur any time and also advised to ready at least four blood donors. Her $2^{\text {nd }}$ USG scan at 26 wks showed placenta bipartite and insertion of cord over the internal os of cervix. Patient was treated conservatively and dose of inj. Oradexon was completed at $32 w k s$ for lung maturation. At 36 weeks, patient perceived less foetal movement and then emergency LUCS with BLTL was done. Baby was well and her postpartum period was uneventful.
\end{abstract}

Introduction:

A bilobed placenta is a placental morphological variation and refers a placenta separated into two near equal lobes. If more than two lobes are present, It is termed as trilobed, four lobed and so on ${ }^{1}$. Usually in singleton pregnancy, there is one placenta and one cord. But bilobed placenta is thought to result from localized atrophy as a result of poor decidualization and vascularization in a part of the uterus ${ }^{2}$. Usually it is associated with velamentous insertion of cord.

\section{Case Report:}

We report a case of 23 years young multigravida with previous history of 2 caeserean section, a booked patient was on regular antenatal care (ANC) in our private hospital. All of her physical findings and routine investigation was normal. But her early USG at 16 weeks gestation was diagnosed as a case of Placenta praevia. Fetal anatomical evaluation was normal and fetal growth was adequate.

Then she was advised to take complete bed rest, avoid journey and coitus. Couple was warned about pervaginal bleeding, which may occur at any time and also advised to keep ready at least four blood donors. Planned USG was done at 26 weeks, which showed placenta bipartite, the anterior and the posterior placental structure was equal in size and insertion of the cord was over the os. Placental maturity was grade 0 .

Couple again advised strictly to take bed rest, avoid journey and coitus and in any emergency immediate hospitalization was advised. Next follow up USG was done at 33 weeks and showed central placental praevia type-III (Fig.-1). AFI remains normal throughout the pregnancy and baby diagnosed as a case of moderate IUGR.

Injection Oradexon $6 \mathrm{mg} 6$ hourly for 2 days was given for lung maturation. She came at $35+$ weeks pregnancy and complained less foetal movement. Her Biophysical profile was 6/8.

Caeserean section and bilateral tubal ligation was decided considering antepartum foetal distress. The post delivery placental pathology was diagnosed as a bilobed (two placental disks) placenta with membranous vessels connecting the placental structures (Fig. 2A and 2B). Her peroperative and postoperative period was uneventful. Baby was under supervision of paediatrician and was well. Mother was advice for exclusive breast feeding

1. Junior Consultant (Gynae \& Obs), Railway General Hospital, Kamolapur, Dhaka.

2. Radiologist, Medisun Health Care \& Hospital.

3. Junior Consultant (Gynae \& Obs), Upozila Health Complex, Tala, Satkhira

4. Anesthetist, Islamia Al Raji Hospital, Dhaka. 


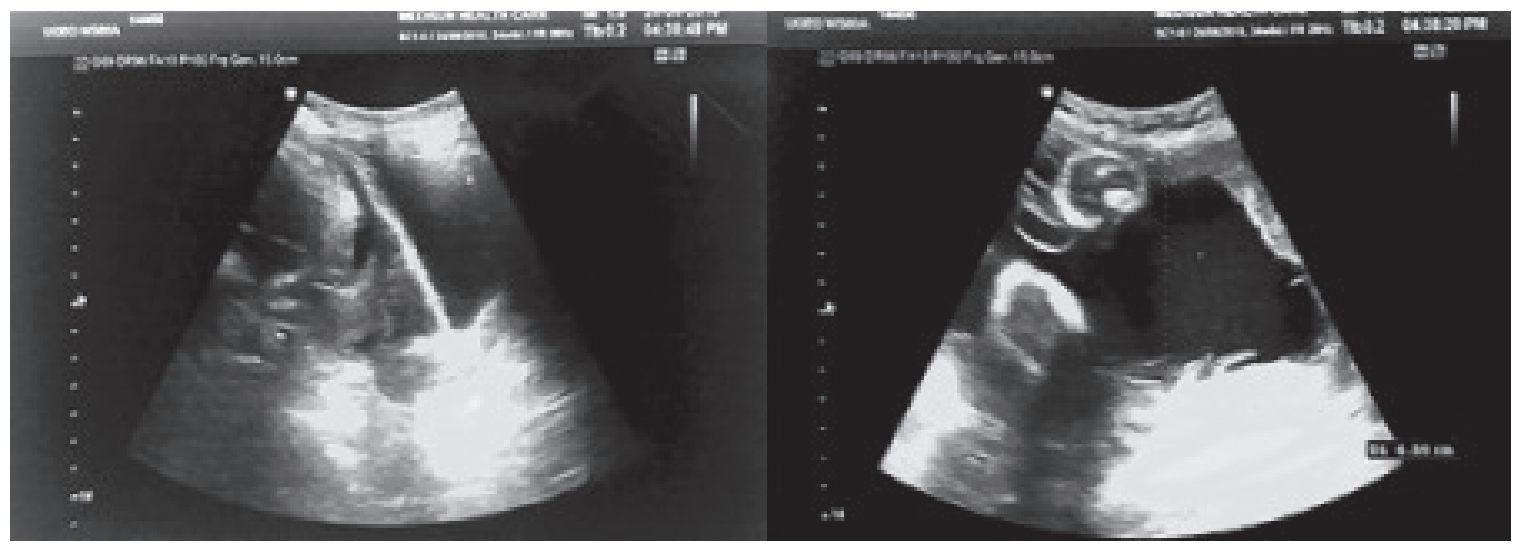

(A)

(B)

Fig.-1 (A, B): Single live foetus of about 33 weeks size with central placenta praevia

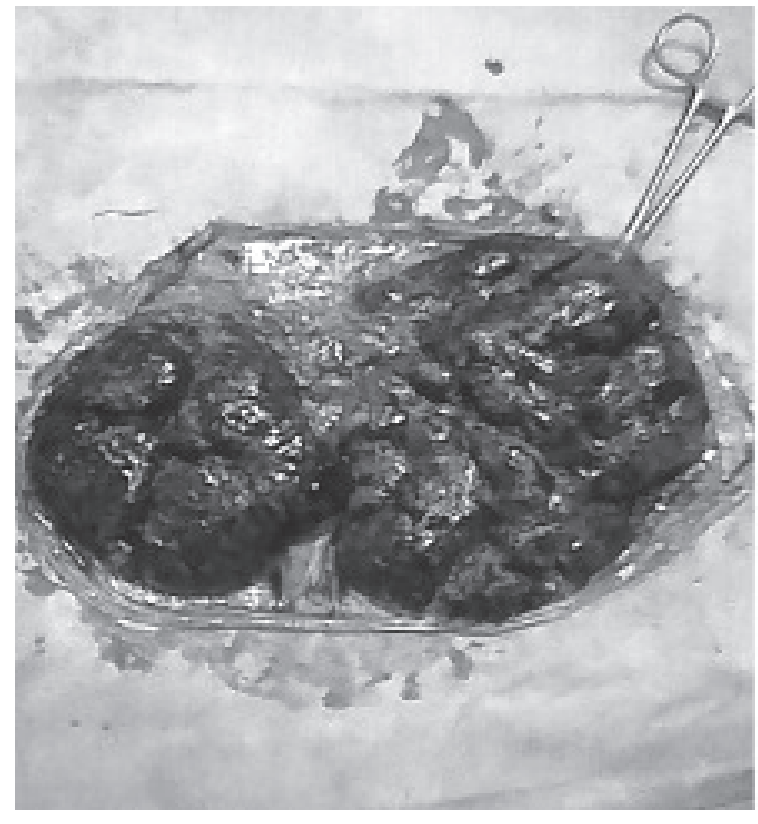

(A)

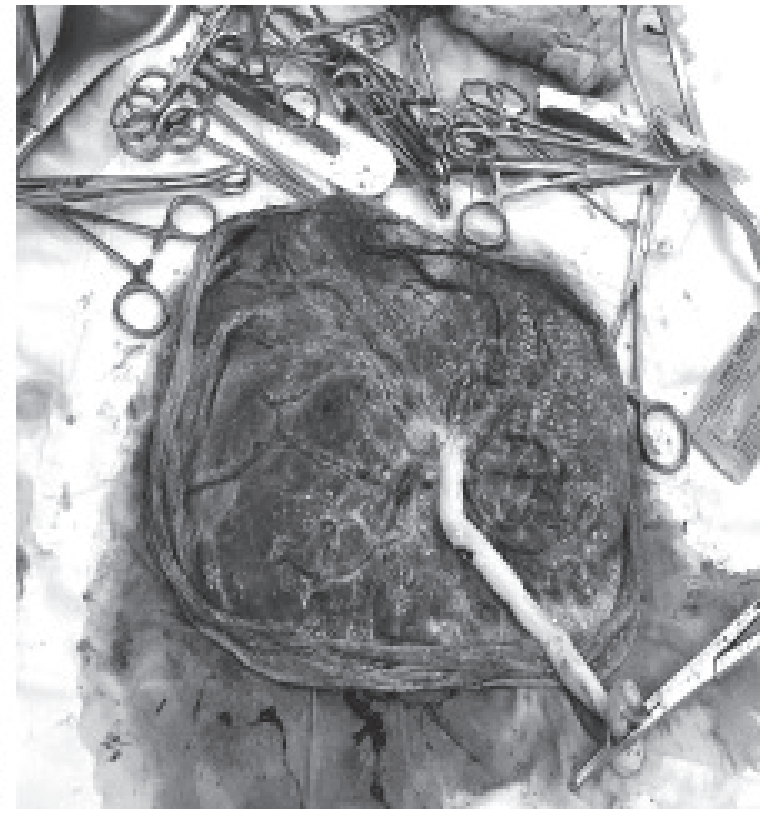

(B)

Fig.-2 (A, B): Bilobed placenta discovered after caesarean section

\section{Discussion:}

The bipartite of bilobed placenta is classified as two placentas separated by a membrane of equal or nearequal size. This is a very interesting case because near the insertion umbilical cord equally divided into two parts and equal blood supply to both lobes. In single normal pregnancy - usually there is one placenta and one cord. Placenta maturity in 1st trimester is 0 and 1, 2 in 2nd and 3rd trimester respectively. In case of this patient, in 1 st trimester it was diagnosed as placenta praevia. Next planned 26 weeks scan showed bilobed placenta. The 33 weeks scan found central placenta praevia. But after LUCS it was found 2 equal size placenta with one cord, and placenta bipartite was confirmed retrospectively.

A bilobed placenta is a variation in the normal shape of placenta. It is usually not associated with an increased risk of foetal anomalies. Risk factors are : advanced maternal age ( $>35 \mathrm{yrs}$ ), maternal history of infertility, cigarette smoking, DM. Causes of bilobed placenta may be - implantation in areas of decreased blood supply, implantation on uterine fibroid, 
implantation in area of previous surgery, implantation over cervical opening. In our case placenta was implanted over cervical os. The presence of bilobed placenta dose not result in higher risk of foetal anomalies. There is an increased risk of bleeding during and after delivery. But prognosis is excellent with suitable care and management. If patient complain pervaginal bleeding in early pregnancy -bilobed placenta should be kept in mind and follow up USG should be done. Our patient has previous history of 2 cesarean section. The number of previous cesarean deliveries did not have a significant effect on placental location. Rather it is associated with increased number of posterior placenta. ${ }^{3}$

Normal development of the placenta occurs as trophoblastic cells (syncytiotrophoblasts) invade walls of the endometrium. The trophoblast developed a membrane (chorion) with projections called the chorionic villi that extend into the blood sinuses of the decidua basalis. This is the foundation of the placenta. It is in the first five weeks of gestation that placental fetal circulation is established by blood vessels extending from the embryo into the chorionic villi and forming the umbilical vein and arteries. The completion of the placenta formation occurs at approximately eight weeks gestation as the villi on the decidua capsularis get atrophied, leaving a smooth surface called the chorion leave. Remaining chorionic villi proliferate into the decidua basalis, establishing the main placental body or the chorionic frondosum, the fetal component of the placenta. By the third month, the formation of cotyledons is established by the partitioning of villi infolding into the decidua basalis.

There is not much literature on the pathophysiology and etiology of the bilobed placenta. Bipartite formation has been theorized as either superficial implantation of the ovum into the decidua or the blastocyst itself attaching to the anterior and posterior walls of the uterus. The bipartite placenta appears to have similar pathogenesis as the succenturiate lobe. This case and the others have demonstrated that the bilobed placenta can be diagnosed as early as 26 weeks gestation. ${ }^{4,5}$ With good obstetric care, skilled sonologist, modern machine, skilled anesthetist and paediatrician - this can be managed without complication. ${ }^{6}$

\section{Conclusion:}

There is no method, which can prevent a bilobed placenta. Proper antenatal care is essential to ensure a healthy pregnancy and uncomplicated delivery. If early USG shows more than 1 lobe of placenta then serial follow up USG should be done for confirmation. Serial scanning in combination with transvaginal and color flow Doppler mapping is the most effective method in diagnosing umbilical insertion. Prenatal diagnosis of bilobed placenta may minimize postpartum complications associated with retained placenta or antepartum hemorrhagic from vasa praevia.

\section{References:}

1. Fujikura T, Benson RC, Driscoll SG. The bipartite placenta and its clinical features. Am. J. Obstet. Gynecol. 1970;107 (7): 1013-7.

2. Baergen RN, Benirschke K. Manual of Pathology of the Human Placenta. Springer Verlag. (2010) ISBN:1441974938

3. Naji, O., Daemen, A., Smith, A. et al, Does the presence of a cesarean section scar influence the site of placental implantation and subsequent migration in future pregnancies: a prospective case-control study. Ultrasound Obstet Gynecol. 2012;40:557-561

4. Valero G, Jeanty P: Sucenturiate and bilobed placenta. Unpublished raw data. Available at www.thefetus.net Accessed August 18,2001.

5. Nelson LH, Fishburne JI, Stearns BR: Ultrasonographic description of succenturited placenta. Obstet Gynecol 1977;49(1 suppl): 79-80.

6. Kleile, H.O, [unusual placental form, annular placenta, bilobed placenta] journal of diagnostic medical sonography. 1956; 18(3). 161-166. 